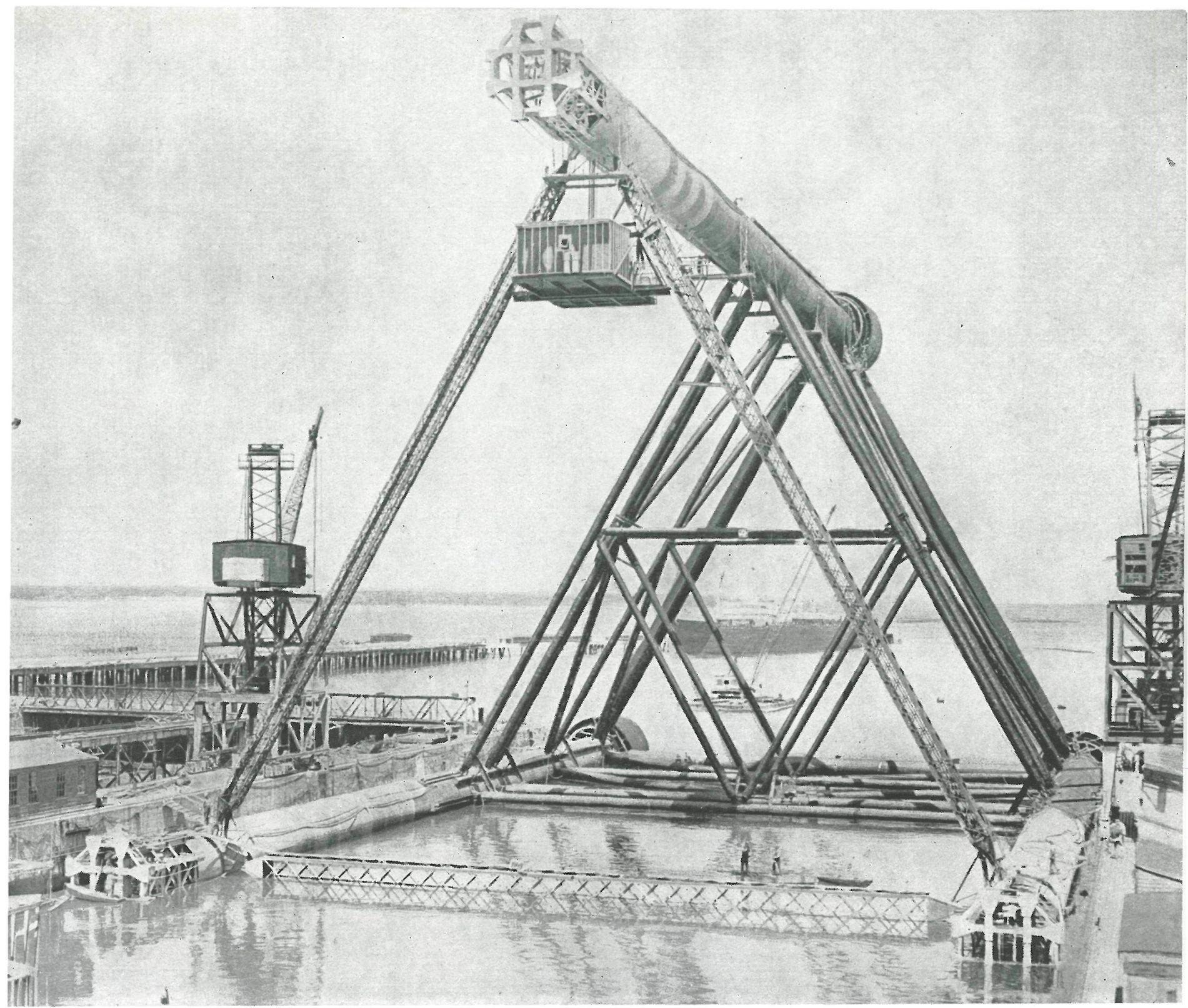

$849-7$

\title{
estación de radar sobre el mar
}

\section{Generalidades}

Para el programa defensivo de los EE. UU. se ha previsto una serie de cinco estaciones de radar, que, situadas sobre torres, emergerán en el mar a una distancia considerable de la costa. De las cinco estaciones ya están en servicio dos en la costa de Tejas.

La tercera, que constituye el objeto de este trabajo, está en construcción en el Atlántico, a unas 60 millas al sureste de Sandy Hook y a unas 100 millas de la ciudad de Nueva York.

\section{Descripción de la obra}

Esta estación está constituída por un castillete metálico, de forma prismática, con sección en triángulo equilátero de $46 \mathrm{~m}$ de lado y una altura total de $95,40 \mathrm{~m}$. Los montantes son tubos metálicos, de $3,80 \mathrm{~m}$ de diámetro, provistos, en su parte inferior, de un cajón cilíndrico, de 7,60 $\mathrm{m}$ de diámetro, que lleva un borde cortante en su extremidad para facilitar la penetración del montante en el fondo del mar.

Las torres de Tejas se han construído a 15 y $24 \mathrm{~m}$ de profundidad de agua, mientras que la que describimos se apoya en un fondo de 55 metros. 


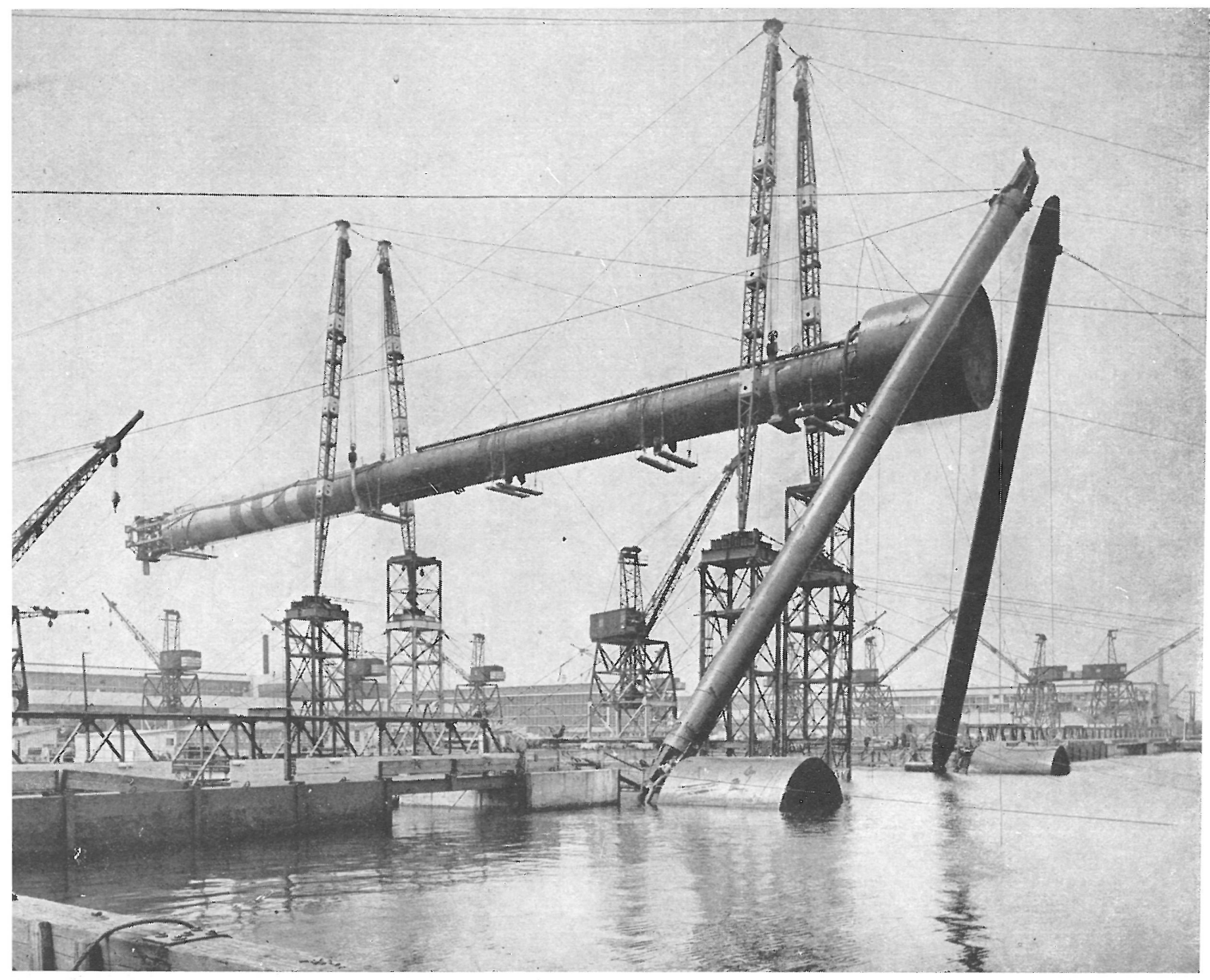

Montaje del castillete.

Fotos: CONTINENTAL COPPER \& STEEL INDUSTRIES

Los tres montantes del castillete se han arriostrado con elementos tubulares, fijados sólidamente entre los montantes y entre ellos mismos, constituyendo una celosía robusta.

La parte superior del castillete se ha coronado con una plataforma, donde se instalará la estación de radar y alojamiento para el personal de servicio de la instalación de localización por radar.

\section{Procedimiento constructivo}

Se procedió, primeramente, a montar el castillete en posición horizontal en una dársena próxima al lugar donde debía colocarse definitivamente la torre.

Terminado el montaje del castillete tubular, para el que se había calculado un empuje ascensional suficientemente grande para hacerle flotar, se remolcó hasta el lugar de ubicación. Una vez en posición, y procediendo desde una cabina de mando suspendida, se dió entrada al agua de lastre. A medida que entraba el agua, el castillete se iba inclinando y hundiendo hasta llegar a la posición vertical, momento a partir del cual desciende en el mismo sentido hasta llegar al fondo del mar.

\section{Montaje}

Esta operación, dirigida y proyectada por la casa M. W. Kellogg Company, de Nueva York, constituyó el núcleo central del conjunto de esta construcción.
Preparados ya los tres montantes del castillete, se levantó uno de ellos a unos dos metros de altura y se apoyó convenientemente. Este montante, que, como los otros dos, pesa 450 toneladas, debía formar la parte superior del prisma triangular flotante.

Después se colocaron los otros dos que forman la base del prisma, se arriostraron $\mathrm{y}$, acto seguido, se prepararon las riostras tubulares, flotantes también, colocadas en posición semi-vertical y sujetadas con vientos que, una vez elevado el tercer montante a su posición definitiva, debían fijar a éste solidariamente con el conjunto.

Todo preparado de esta forma, se procedió a levantar, por medio de cuatro plumas, el tercer montante a su posición final, emparejadas dos a dos, de $33,60: \mathrm{m}$ de longitud y apoyadas sobre unos entramados de sección cuadrada, de $3,60 \mathrm{~m}$ de lado y 19,50 $\mathrm{m}$ de altura. La longitud de cada montante es de 95,70 m; la distancia entre estos dos aparejos, de dos plumas cada uno, es de $46 \mathrm{~m}$, y entre los ejes de las dos plumas de cada aparejo se dejó una distancia de 12 metros.

Todo preparado como se ha dicho, se levantó el tercer montante a la altura convenida y se procedió después a su fijación con los elementos que constituyen el arriostramiento.

Terminado el montaje, se retiraron los aparatos y torres auxiliares para el montaje, quedando la estructura flotando sobre el agua y lista para ser llevada por un remolcador al lugar de su emplazamiento.

J. J. U. 